\title{
Pathologies elicited by the gymnophallid metacercariae of Bartolius pierrei in the clam Darina solenoides
}

\author{
Florencia Cremonte* and Cristián Ituarte $^{\dagger}$ \\ * Centro Nacional Patagónico (CONICET), Boulevard Brown s/nº, 9120 Puerto Madryn, Chubut, Argentina, \\ e-mail: fcremont@cenpat.edu.ar; 'División Zoología Invertebrados, Museo de La Plata, 1900 La Plata, Buenos Aires, Argentina
}

\begin{abstract}
Darina solenoides (Mactridae), a common intertidal bivalve in the Argentine Patagonian coast, serves as both first and second intermediate host for the gymnophallid Bartolius pierrei (Trematoda: Digenea). Cercariae enter the clams actively by piercing the mantle border; young metacercariae ascend along the space between the outer mantle epithelium and shell and they settle in the dorsal general extrapallial space just ahead of the posterior adductor muscle. Host reaction comprises mantle tissue alterations (hyperplasia and metaplasia) leading to the encapsulation of the metacercariae by the formation of a one-cell-layer thick sac, which progressively detaches from the mantle epithelium. Sacs containing fully developed metacercariae, which are surrounded by a hyaline non-cellular envelope, become internal and are found in the postero-dorsal region of the visceral mass. Two sacs usually containing from two to 44 metacercariae, one at each side of the clam, were observed. In some cases, in which the infection seems not to proceed as usual, dead and dying metacercariae and their debris were found in the same position within the extrapallial space where the host reaction usually starts. In these cases, the mantle reaction is accompanied by an inner shell surface alteration consisting of calcium carbonate deposits partially surrounding the reaction complex or other abnormal calcifications in the form of loose mineral concretions.
\end{abstract}

\section{INTRODUCTION}

With few exceptions, larvae of members of the family Gymnophallidae Odhner, 1905 (Trematoda: Digenea) are parasites of marine bivalves; their adults parasitize coastal birds (Bartoli, 1974; Ching, 1995). Gymnophallid metacercariae are almost always located in the space between mantle and shell (the extrapallial space), and often cause the formation of pearls or a variety of calcium carbonate concretions, for this reason they have been largely known as 'pearl trematodes' (Jameson, 1902; Lauckner, 1983). However, the host-parasite interactions between bivalves and gymnophallids do not always lead to the formation of pearls. Many different reactions have been reported worldwide, varying from the lack of host reaction to the formation of a gelatinous covering, igloo-like structures, pits in the inner shell surface, and even changes in host behaviour (Lauckner, 1983). It was reported that the wide range of host reactions are dependent not only on the host and parasite species involved but also on the specific location of metacercariae in the extrapallial space (Bartoli, 1974; Lauckner, 1983; Campbell, 1985; Bowers et al., 1996; Ituarte et al., 2001). Even the same parasite, such as for example Meiogymnophallus fossarum (Bartoli, 1965), has been reported as eliciting different responses in the same host species according to the position their larvae occupy in the extrapallial space (Bartoli, 1974). In Gaimardia trapesina (Lamarck, 1819) (Bivalvia: Gaimardiidae), Ituarte et al. (2001) reported that not all parasite species, despite occupying the same location in the host, evoke the same host reaction.

Darina solenoides (King \& Broderip, 1832) (Bivalvia: Mactridae) is distributed in the southwestern Atlantic
Ocean along the intertidal of sandy beaches from San Matías Gulf to Magellanic Region (Carcelles, 1950). This bivalve acts as both first and second intermediate host for the gymnophallid Bartolius pierrei Cremonte, 2001 at Península Valdés, Argentina (Cremonte, 2001). The adult parasitises the kelp-gull Larus dominicanus Lichtenstein, 1823 (Laridae), and probably other birds that feed on that clam (i.e., Calidris canutus Wilson, 1813 (Scolopacidae)) (Cremonte, 2001).

The aim of this work is to describe, from natural and experimental infections, the response of the clam Darina solenoides to the metacercariae of the gymnophallid Bartolius pierrei at both individual and cellular levels.

\section{MATERIALS AND METHODS}

Specimens of Darina solenoides were collected from August 1999 to March 2001 from the sandy littoral at Fracasso Beach $\left(42^{\circ} 25^{\prime} \mathrm{S} ; 64^{\circ} 07^{\prime} \mathrm{W}\right)$, San José Gulf, Argentina. The clams were examined for metacercariae and immediately fixed in either $10 \%$ seawater formalin solution or in Davidson's fixative. To study the development of host reaction, experimental infection assays were conducted in November 2000 as follows: immediately after collection, about 200 clams were placed in individual flasks and observed twice a day for cercariae emission (cercariae were expelled through the exhalant syphon). Unparasitized small clams (less than $12 \mathrm{~mm}$ in shell length) were isolated, and then exposed to a large number of cercariae (the thin and translucent shell allowed us to determine the health condition of these clams, by means of direct inspection of 


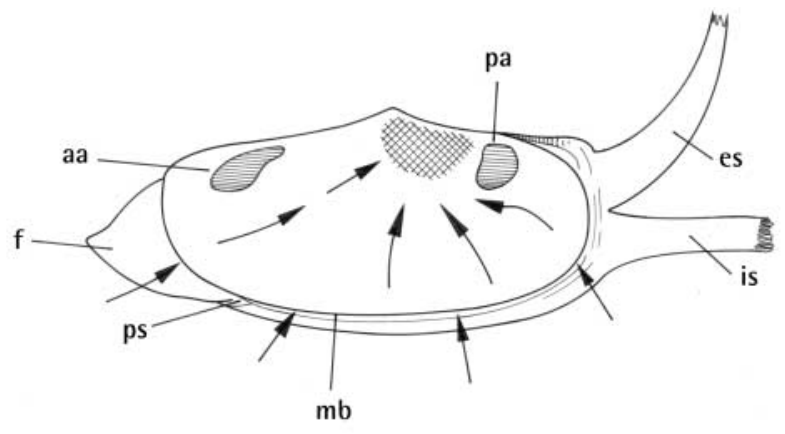

Figure 1. Schematic view of soft part of Darina solenoides showing ways of cercariae penetration and metacercariae definitive habitat (shadow area). aa, anterior adductor muscle; es, exhalant syphon; $f$, foot; is, inhalant syphon; mb, mantle border; pa, posterior adductor muscle; ps, pedal slit.

tissues under a stereoscopic microscope). The experimentally infected clams were maintained for up to 23 days in an aquarium, being sacrificed and processed for histology at different time intervals. Specimens for histology were fixed in a $10 \%$ seawater formalin solution; whole specimens were post-fixed and decalcified by $24 \mathrm{~h}$ rinse in a $5 \%$ formalin solution added with $2 \%$ of acetic acid prior to dehydrating in ethanol $96 \%$ and N-butylic alcohol, embedding in Paraplast ${ }^{\circledR}$, sectioning $(7 \mu \mathrm{m}$ thick) and staining with haematoxylin-eosin (Gabe, 1968). Final stages of the infection process were studied upon naturally infected bivalves from field collections.

To establish the infection load of B. pierrei, a total of 90 specimens of $D$. solenoides of three size-classes $(8-12,13-16$ and $17-23 \mathrm{~mm}$ in shell length) were collected in March
$(\mathrm{N}=60)$ and November $2000(\mathrm{~N}=30)$, and fixed immediately in a seawater $10 \%$ formalin solution. The presence of small young metacercariae, large old metacercariae, number of sacs per clam, and presence of abnormal calcifications, were quantified (we considered as 'young metacercariae' those larvae translucent in appearance and free in the general extrapallial space, and as 'old metacercariae' those dark in appearance due to the accumulation of refringent calcareous granules within the excretory bladder and enveloped in sacs in the visceral mass). Valves of specimens used for the scanning electron microscope (SEM) study were treated for five minutes with a $10 \%$ solution of commercial sodium hypochlorite and rinsed in distilled water prior to mounting and coating for observation. Parasitological indices were calculated according to Bush et al. (1997).

In order to investigate the chemical nature of larvae encapsulation, sections of naturally infected clams were stained with the Alcian blue/periodic acid-Shiff's (AB/ PAS) method (Gabe, 1968) for acid and neutral mucopolysaccharides. For comparative purposes, the normal histology of mantle tissues was studied in healthy, unparasitized individuals. Nomenclature regarding metacercariae habitats in the extrapallial space follows Bartoli (1974).

Voucher specimens (histological sections and whole parasitised clams) were deposited at the Malacological Collection, Museo de La Plata, La Plata, Argentina (MLP 6506 and 5694 respectively).

\section{RESULTS}

The cercariae of Bartolius pierrei entered the second intermediate host actively by piercing the mantle border, which in Darina solenoides is widely fused along the ventral
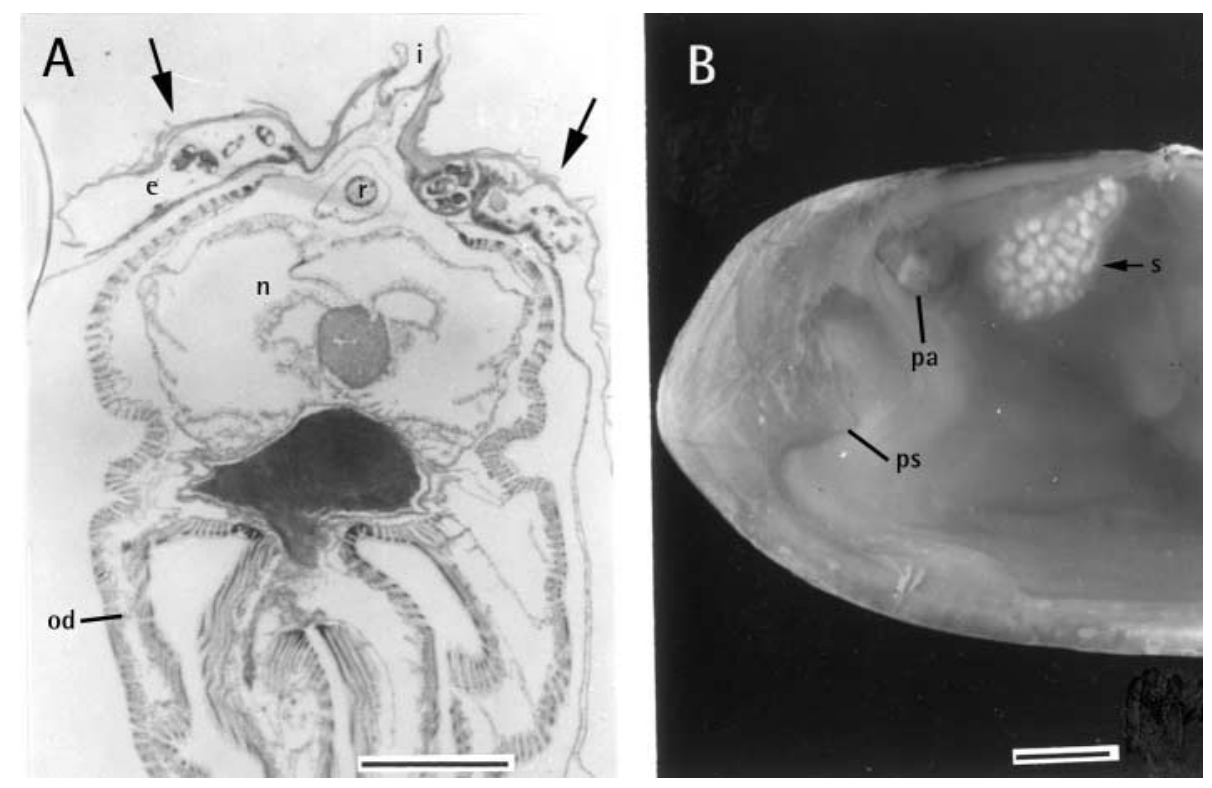

Figure 2. Location of Bartolius pierrei metacercariae in the bivalve host naturally infected. (A) Transverse histological section through the posterior end of a clam specimen showing a bilateral infection by metacercariae, and the relative position of larvae aggregates in the clam (arrows). Right and left sides of the specimen show the dorsal part of the extrapallial space greatly expanded (Scale bar $=0.5 \mathrm{~mm}$ ). (B) Lateral view of the posterior end of a specimen of Darina solenoides (right valve has been removed) showing the location of a very large sac within the visceral mass containing numerous metacercariae (Scale bar $=1 \mathrm{~mm})$. e, extrapallial space; i, mantle isthmus; n, nephridium; od, outer demibranch; pa, posterior adductor muscle; ps, pallial sinus; r, rectum; s, sac containing metacercariae. 


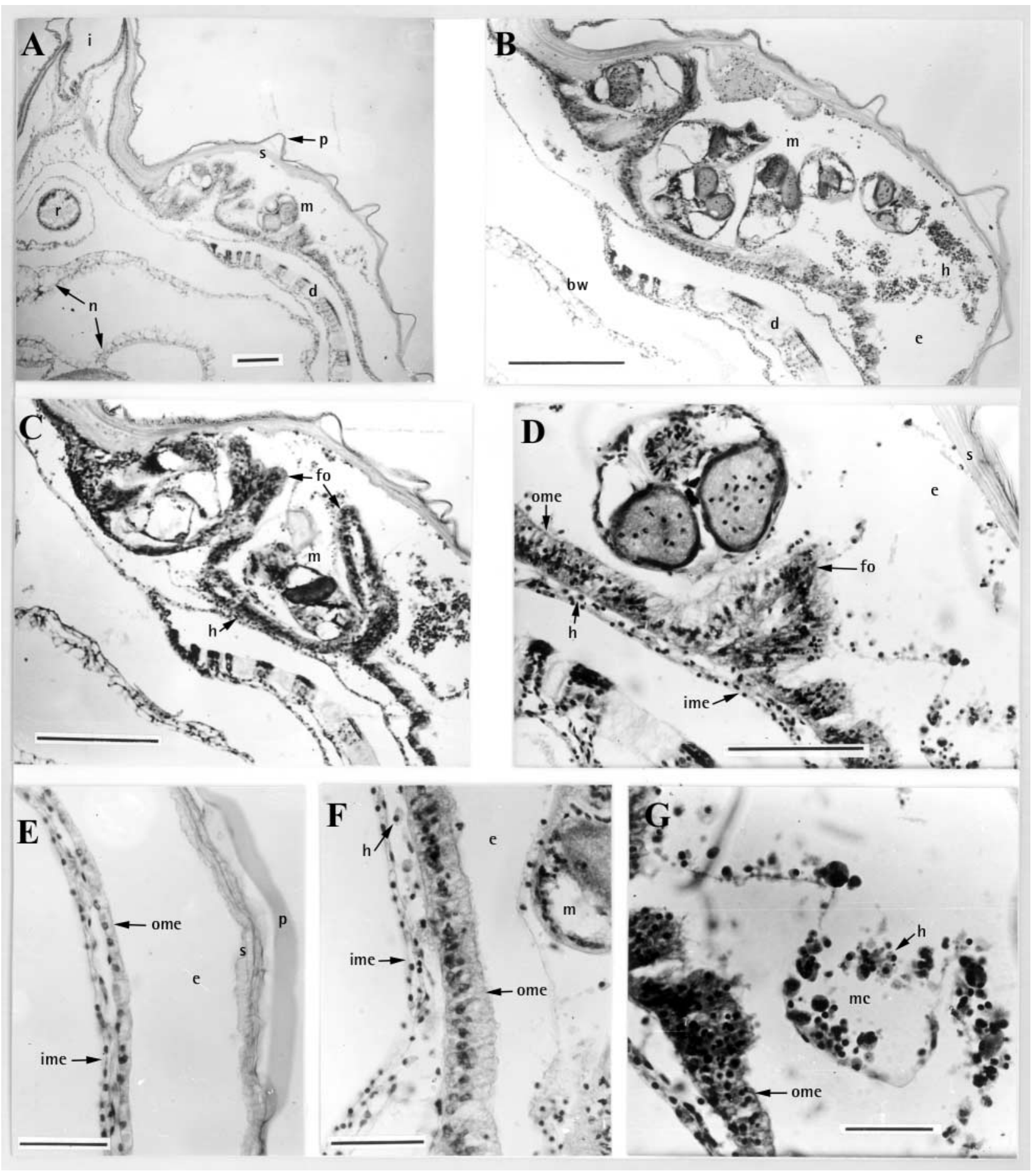

Figure 3. Initial phase of the encapsulation process of Bartolius pierrei metacercariae in the clam Darina solenoides. (A) Recently settled metacercariae; mantle already shows a strong reaction. (B) Numerous metacercariae in the definitive habitat determining the enlargement of the extrapallial space. (G) Mantle folding surrounding metacercariae. (D) Detail of A showing outer mantle epithelium hypertrophia. (E) Normal histology of mantle tissues. (F) Metaplasia and hyperplasia of the outer mantle epithelium (note the granular content of cell cytoplasm). (G) Cells debris and multinucleate corps coming from the lysis of the mantle epithelium in the acute phase of the host response (Scale bars for A, B, and $\mathrm{C}=100 \mu \mathrm{m} ; \mathrm{D}=50 \mu \mathrm{m} ; \mathrm{E}, \mathrm{F}$ and $\mathrm{G}=20 \mu \mathrm{m}$ ). d, demibranch; e, extrapallial space; fo, mantle folds; h, haemocytes; i, mantle isthmus; ime, inner mantle epithelium; m, metacercariae; n, nephridium; mc, multinucleated corps; ome, outer mantle epithelium; p, periostracum; r, rectum; s, shell matrix; bw, body wall.

margin, excluding the small anterior pedal slit (Figure 1). When the general extrapallial space was gained, larvae moved upwards crawling between the outer mantle epithelium and the inner shell surface gathering in a specific area located in the dorsal region of the general extrapallial space, just forward of the posterior adductor muscle (Figures $1 \& 2$ ). The young metacercariae reached their final location within 24-72 hours.

Aggregates of metacercariae occurred at both right and left mantle dorsal lobes (Figure 2A). The extrapallial space, 

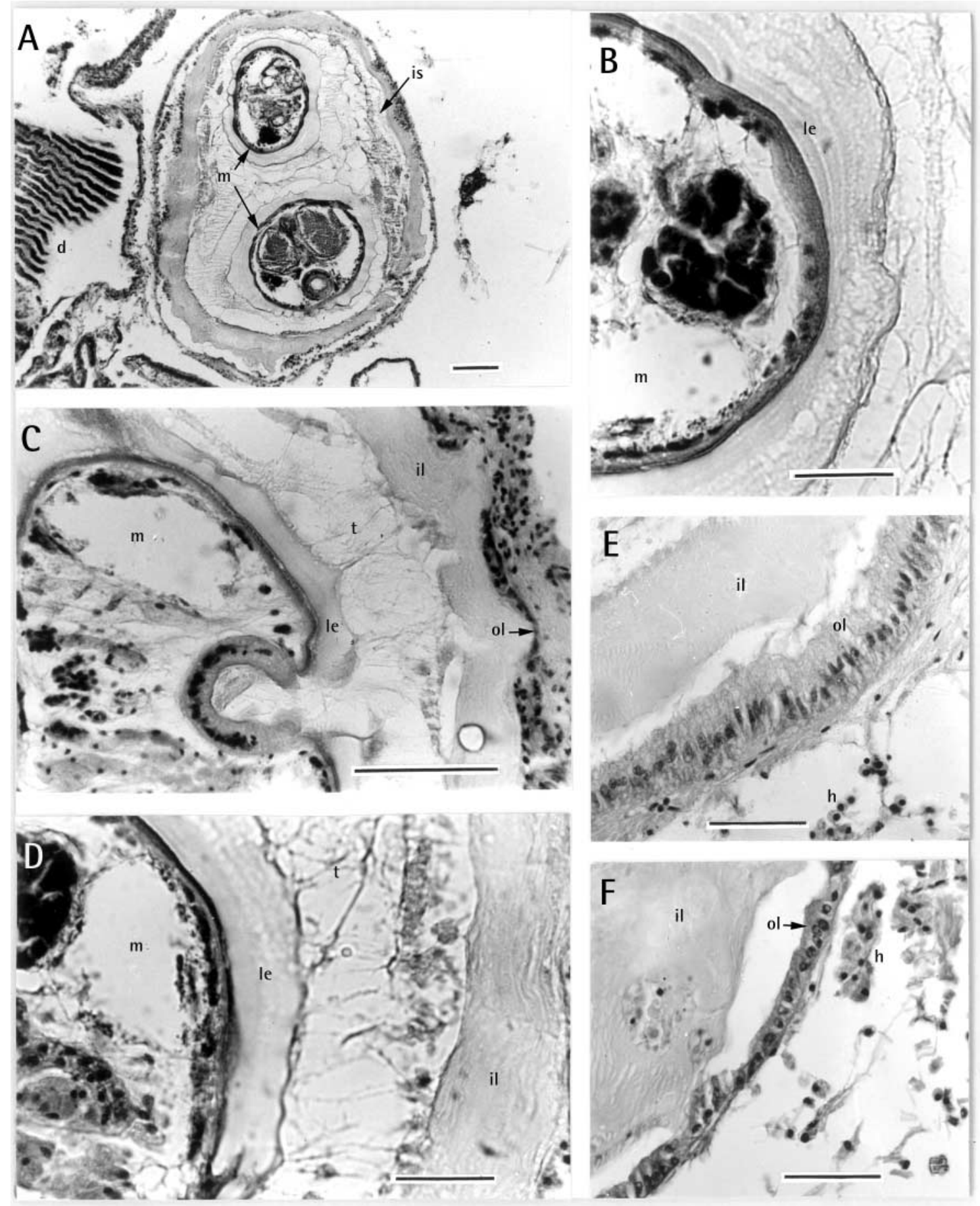

Figure 4. Final phase in the encapsulation process of Bartolius pierrei metacercariae. (A) Sac completely formed within the visceral mass. (B) Detail of the closely adhered non-cellular hyaline metacercaria envelope. (C) General view of the sac wall. (D) Detail of the inner layer of the sac wall and larval hyaline envelope. (E) Detail of the outer cellular layer of the wall of a recently formed sac. (F) Detail of the outer cellular layer of an older sac (note differences in cell shape respect to E. Scale bars: A, C = $100 \mu \mathrm{m}$; B, D, E and $\mathrm{F}=20 \mu \mathrm{m}$ ). d, demibranch; h, haemocytes; il, inner layer of the sac; is, internal sac; le, larva envelope; m, metacercariae; ol, outer layer of the sac wall; $t$, net of trabecules.

which is in fact nearly a virtual space between the outer mantle epithelium and the inner shell surface, enlarged greatly after the settlement of the metacercariae, mainly when they are found to be in large quantities (Figure 3A,B). When the metacercariae settled, an increasing number of haemocytes accumulated in the extrapallial space adjacent to larvae (Figure 3B); also a slight increase in the current number of haemocytes was observed between both the inner and the outer mantle epithelium (Figure $3 \mathrm{C}-\mathrm{F})$. About five to six days post-infection, the outer mantle epithelium adjacent to the larvae showed signs of hypertrophy, and started to proliferate (hyperplasia) forming a series of projections and folds towards the extrapallial space that progressively surrounded the metacercariae (Figure 3C, D). The cells of the outer mantle epithelium in the vicinity of metacercariae also 
Table 1. Infection load of the gymnophallid metacercariae Bartolius pierrei in the clam Darina solenoides, at Fracasso Beach, San Fosé Gulf, Argentina.

\begin{tabular}{llllllllll}
\hline Date & N & Clam size* & P y.m. & I y. m. & P o.m. & No. of sacs & o.m./sac & I o. m. & Calcifications \\
\hline March 2000 & 20 & $10(8-12)$ & $40 \%$ & $2(1-3)$ & $10 \%$ & $1.0(1)$ & $8(6-10)$ & $8(6-10)$ & 0 \\
& 20 & $14(13-16)$ & $100 \%$ & $8(1-18)$ & $10 \%$ & $2.5(1-4)$ & $25(13-38)$ & $25(13-38)$ & $20 \%$ \\
\multirow{2}{*}{ Nov. 2000 } & 20 & $20(19-22)$ & $70 \%$ & $4(2-11)$ & $32 \%$ & $3.0(1-5)$ & $11(2-44)$ & $21(3-40)$ & $5 \%$ \\
\hline
\end{tabular}

*, maximum length in $\mathrm{mm}$; $\mathrm{P}$, prevalence of infection; y.m., young metacercariae (still free in the general extrapallial space), I, intensity of infection; o.m., old metacercariae (enclosed in sacs in the visceral mass); o.m./sac, old metacercariae per sac, calcifications, percentage of abnormal calcification (in all counts and calculations, mean values are followed by ranges in parentheses).
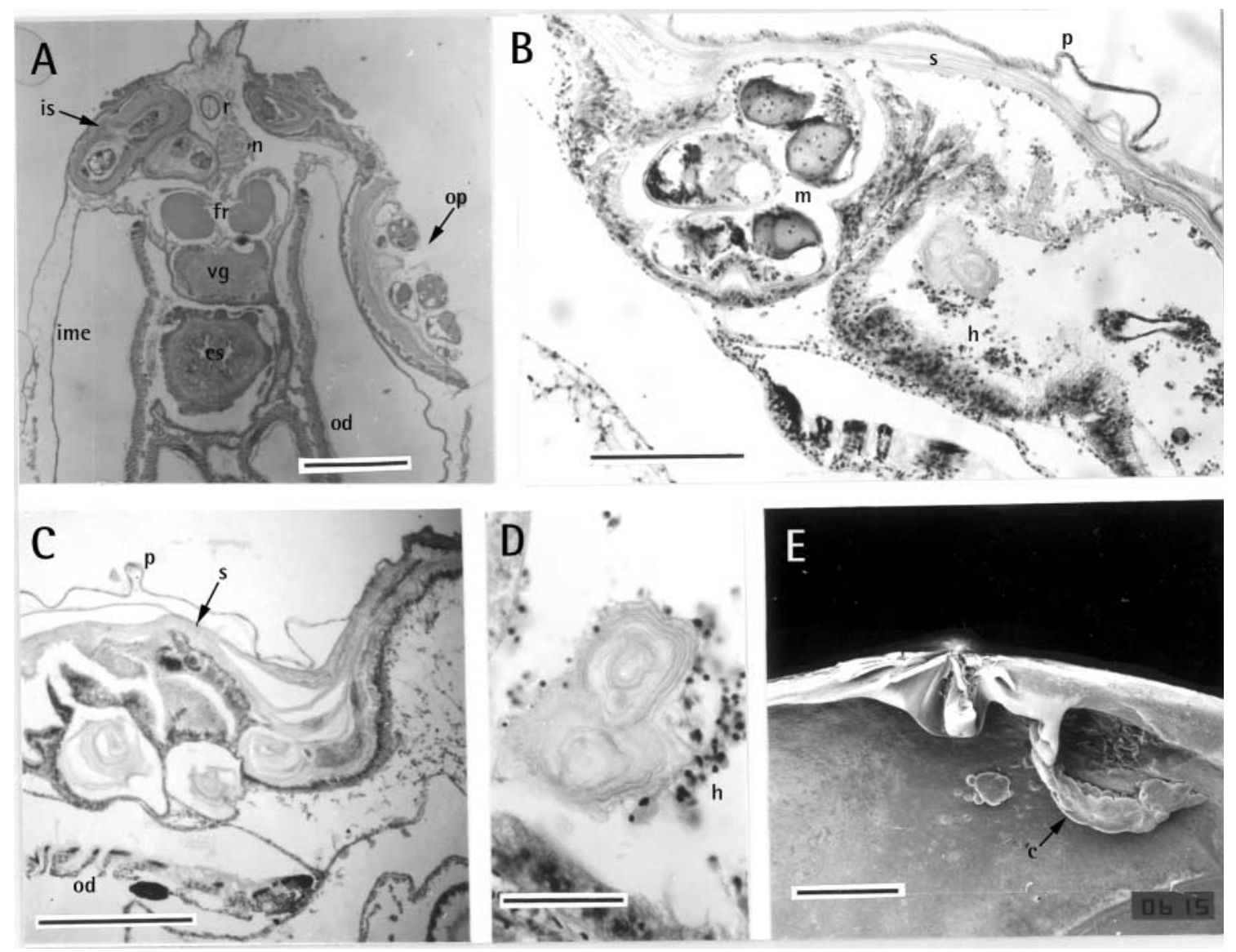

Figure 5. Abnormal processes of larvae encapsulation. (A) Transverse section of a specimen of Darina solenoides showing both normal (left) and abnormal (right) encapsulation processes. (B) Coexistence of normal developing metacercariae and remains of calcifications. (C) Successful host reaction against larvae. (D) Detail of organic matrix corresponding to a calcium concretion. (E) Inner view of a shell showing abnormal calcification (Scale bars: $\mathrm{A}=1 \mathrm{~mm} ; \mathrm{B}, \mathrm{C}=50 \mu \mathrm{m} ; \mathrm{D}=20 \mu \mathrm{m} ; \mathrm{E}=2 \mathrm{~mm}$ ). es, exhalant syphon; c, calcium ridge; fr, foot retractor muscles; h, haemocytes; ime, inner mantle epithelium; is, internal sac; m, metacercariae; n, nephridium; od, outer demibranch; op, open pouch; p, periostracum; r, rectum; s, shell matrix; vg, visceral ganglion.

showed metaplasia, cell shape changes from cubic to cylindrical and cytoplasm showed an increasing number of secretion granules (Figure 3E, F). During this process, at least part of the outer mantle epithelium cells undergo lysis. Dense aggregates of cell debris, multinucleated basophilic corps and clumps of haemocytes accumulate in the extrapallial space close to the newly settled larvae (Figure 3B-D \& G).

Approximately 23 days post-infection, the metacercariae were surrounded by the reaction tissue derived from the outer epithelium of the mantle, but still having connection with the extrapallial space. At this initial stage, the encapsulation also contained cell debris, multinucleated corps derived from the lysis of mantle tissues, and a number of haemocytes. In this way, a variable number of metacercariae, ranging from two to 44 resulted bounded in rounded sacs (approx. $2.2 \times 2.5 \mathrm{~mm}$ in size, depending on the number of metacercariae they contained).

At late stages of the encapsulation process, the sac lost contact with the extrapallial space and mantle epithelium, then sunk in the dorsal portion of the visceral mass, lying immediately below the dorsal shell margin, 
above the nephridia, and at the side of the rectum. A twolayer wall bound the sac containing enveloped metacercariae (Figure 4A, B). The outer layer is a one-cell-thick epithelium whose cells were, at the end of the sac formation, most similar to those in the normal outer mantle epithelium (Figure 4C-F); and the inner, a PAS positive, non-cellular layer $(50-70 \mu \mathrm{m}$ thick), which seemed to be built up by multiple concentrically arranged thin layers (Figure 4C, D). Discrete aggregates of haemocytes were frequently seen between both layers of the sac wall. Each larva was enveloped by a closely adhered non-cellular, hyaline wall (20-25 $\mu \mathrm{m}$ thick) strongly alcianophilic and PAS negative, indicating the presence of acid mucopolysaccharides (Figure 4A-D). The same strongly positive stain reaction with Alcian blue was shown by the integument surface of the larvae. In freshly examined specimens the envelope had a gelatinous aspect, impossible to separate from the body of the larvae. In the case of the inner layer of the sac wall, the gelatinous envelope covering each metacercariae also showed a multilayered structure. A loose net of trabecules formed by alcianophilic hyaline material connected each enveloped metacercaria to the inner sac wall (Figure 4A, C \& D). As infection proceeded, new sacs formed in the extrapallial space were added to the visceral mass, in a process of continuous increase of the parasitic load.

The infection load of Darina solenoides by Bartolius pierrei at Fracasso Beach, Península Valdés, was highly variable (Table 1). Overall prevalence and mean intensity of infection in March and November $(\mathrm{N}=90)$ in natural populations were found to be $71 \%$ and 15 , respectively. The number of sacs found in larger (older) clams $(17-23 \mathrm{~mm}$ class-size) varied from one to five per clam, whereas in the smaller ones only one sac was usually found (Table 1). An unusual larger clam, $30 \mathrm{~mm}$ in shell length, harboured four sacs with two, 26, 38, and 44 metacercariae each. Even in those cases of low intensity of infection, host reaction was evident, and the mantle of $D$. solenoides showed hyperplasia.

In naturally infected clams, both old stages of infection represented by one or more internal sacs and newly settled metacercariae with different degrees of mantle reaction, were found coexisting in the same individual (Figure 5A,B). In those highly parasitized clams, in which up to five sacs occupied entirely the available space in the visceral mass, the reaction process elicited by new metacercariae settled in the dorsal extrapallial space did not proceed to the formation of internal sacs. In these cases, the reaction led to the formation of a pouch or sac widely open to the extrapallial space, delimited by the inner shell surface and by a two-layer wall identical to that described for the internal sac wall (Figure 5A).

In some cases (five to $13 \%$ of examined specimens of $17-23 \mathrm{~mm}$ class-size), the mantle reaction elicited by the settlement of metacercariae resulted in the initiation of a calcification process in the form of ridges or crests (Figure 5E) tending to bound or isolate the aggregate of metacercariae in the extrapallial space. In these cases, a brownish material resulting from dead larvae accumulated in the extrapallial space. In other cases, calcifications in the form of styles and rounded or irregular concretions were found within the sacs in the visceral mass of the clams. In histological sections of decalcified clams, the organic matrix of calcium concretions appeared as multiple concentric layers (Figure 5B-D).

The presence of abnormal calcifications in the form of loose calcium concretions and growth disruptions in the inner shell surface was a phenomenon associated with relative older infections. They were more frequent in aged clams in which the infection process had reached more advanced stages (five to $13 \%$ of older D. solenoides specimens in which old metacercariae were dominant in number showed calcifications, and none in young bivalves in which the dominant larvae were young metacercariae) (Table 1).

\section{DISCUSSION}

The whole process of encapsulation of Bartolius pierrei metacercariae in the clam Darina solenoides presents two clearly differentiated phases. The first one characterized by an acute host reaction against parasites, it takes place in the boundary of the dorsal general extrapallial space of the bivalve. A moderate infiltration of haemocytes after the larval settlement, followed by hyperplasia and metaplasia of the outer mantle epithelium adjacent to larvae, were the main characteristics of the reaction at this first stage. The second phase of the reaction process, which started in the extrapallial space, leads to the formation of a sac containing the metacercariae, that later lose the connection with the extrapallial space and mantle tissues from which it derives, becomes internal.

The host reaction of Darina solenoides elicited by metacercariae of Bartolius pierrei is rather similar to that described by Bartoli (1974) for the host-parasite system: Donax trunculus (Linné, 1758) (Bivalvia: Donacidae)Meiogymnophallus strigatus (Lebour, 1908) (Digenea: Gymnophallidae). Here, as in the case of B. pierrei, the sacs containing larvae detach from the mantle and become internal; in this way, the metacercariae are permanently taken away from the habitat (i.e.: the dorsal extrapallial space) where they had settled. In Bartoli's (1974) opinion, this fact represents a way to maintain the habitat permanently free of parasites, allowing the continuous settlement of new metacercariae and the steady increase of the parasitic load. Our results agree with this explanation. In small clams (8-12 mm class-size) prevalence of young metacercariae was $40 \%$ and prevalence of old metacercariae was $10 \%$, indicating a relatively new infection. In older clams (larger than $16 \mathrm{~mm}$ shell length) prevalence of old metacercariae varied from 30 to $35 \%$, and the values of prevalence for young metacercariae from 53 to $70 \%$, indicating a continuous incorporation of infective larvae (Table 1). According to Bartoli (1981) the mode of metacercariae recruitment by the second intermediate host depends on the volume of the habitat available for larvae, and it is related to the characteristics of the environment where the parasite life cycle occurs. When the environmental conditions determine a low density of infective larvae, an unlimited recruitment process is viewed as an adaptive character favouring the concentration of infective forms in the second intermediate host.

In cases of old infections as here described, the number of sacs saturate the available space in the visceral mass, precluding the formation of new. This is in agreement with Bartoli's (1981) postulate that the habitat volume limits the gymnophallid larvae recruitment. In these 
heavily parasitized clams, new aggregates of metacercariae that reach the extrapallial space do not evolve as usual, building up a structure functionally equivalent to sacs, such as the formation of open pouches, that remain widely connected to the extrapallial space (Figure 5A).

Sometimes, the reaction elicited by Bartolius pierrei seems not to proceed as usual. A few healthy metacercariae as well as dead and dying larvae, and debris of decaying tissues were found in the dorsal extrapallial space (Figure 5B). In these cases, abnormal calcifications in the form of crests and ridges attached to the inner shell surface or calcium concretions were found within the sacs in the visceral mass of the clams. A similar process was also reported by Goater (1993) in Cerastoderma edule (Linné, 1758) (Bivalvia: Cardiidae) parasitised by Meiogymnophallus minutus (Cobbold, 1859) in southern England. However, in this case, the death of metacercariae was attributed to hyperparasitosis by sporozoans, a fact not observed in B. pierrei metacercariae. Taking into account that these abnormal calcifications were always associated with dead or dying metacercariae, these processes might be interpreted as the result of a successful host response against parasites followed by the isolation of the foreign materials. Campbell (1985) and Ituarte et al. (2001) also reported shell alterations as part of bivalve host reactions elicited by gymnophallid metacercariae.

It is evident that the secretory activity of the external layer of the sac wall originates the non-cellular inner one. Along the process of sac formation, the cells of the outer layer of the sac wall vary in shape and size; this seems to be related to their metabolic activity (Figure 4E\&F). Whether the larva itself secretes the non-cellular envelope that surrounds each metacercaria, or it derives from the inner sac wall, was not possible to be clarified in this work. However, the similar staining affinity (alcianophilia) of both the non-cellular envelope and the surface of larval integument suggest that this envelope is secreted by the parasite. Pekkarinen (1984) reported the alcianophilia and $\beta$-metachromasia of the 'non-cellular capsule' which usually closed the metacercariae against the clam shell of Macoma balthica (Tellinidae), as well as the same reaction of the surface coat of metacercariae of Lacunovermis macomae (Lebour, 1908) (Gymnophallidae). She discussed the origin of this 'capsule', though she was unable to elucidate if it was formed by the parasite itself or by the host. Since gymnophallid metacercariae never encyst (Lauckner, 1983) - contrary to the rule for most digenean metacercariae - the closely adherent envelope could represent a sort of protecting structure (i.e., to avoid digestion in the proventriculus of the final host), such as the cyst wall.

The size increase of the sacs is due to both the secretion of the outer wall and by the growth of metacercariae. Young metacercariae of $B$. pierrei were $234 \mu \mathrm{m}$ long by $234 \mu \mathrm{m}$ wide, and the old ones $612 \mu \mathrm{m}$ long by $355 \mu \mathrm{m}$ wide (Cremonte, 2001). The growth in size of metacercariae is accompanied by the development of the genital system and the dilatation of the excretory bladder, which become filled with calcareous granules. These facts are evidence of a dynamic interaction (feeding, excretion, etc.) between the parasite and the internal host medium.

The host response here described, as well as those evoked by other gymnophallids (Bartoli, 1974; Lauckner, 1983; Ituarte et al., 2001) do not agree with any type of mollusc cell defence mechanisms proposed by Cheng \& Rifkin (1970). In this paper, the final result of the reaction of Darina solenoides to metacercariae of Bartolius pierrei was reported as an 'encapsulation'. However, this term was early defined (Cheng \& Rifkin, 1970) and later on applied (Fletcher \& Cooper-Willis, 1982; Feng, 1988) with a different meaning. Cheng \& Rifkin (1970) defined encapsulation as the process of 'enveloping an invading organism or experimentally introduced tissue too large to be phagocytosed, by cells and/or fibres of host origin'. This author reported that blood cells (here named as haemocytes), connective tissue cells, and myofibres are the only cellular types involved in encapsulation processes, without considering epithelial mantle cells. Based on the present results, it is evident that the involvement of outer mantle epithelium cells (undergoing metaplasia and hyperplasia) to form a sac to isolate $B$. pierrei metacercariae, constitute a dynamic, not a passive walling - off, host cell - response. Due to this fact, and in accordance to Cheng \& Rifkin's (1970) definition, the mantle cell reaction should be considered to be part of a true encapsulation process.

Mantle tissue cells have been only considered as being involved in a cellular host response that was coined as 'nacrezation' by Cheng (1967). Nacrezation, contrary to encapsulation, is assumed to be a non-dynamic process, in which the foreign particle is excluded from the internal host environment by a wall of calcium carbonate formed by multiple layers of nacre. Moreover, this reaction is not considered to be a specific response, likely triggered by any physical pressure on the mantle tissue. In this type of reaction, any particle (sand grain or parasite larva) is engulfed within a 'pearl sac' derived from the invagination of the outer mantle epithelium surrounding the foreign particle; and then layers of nacre are deposited around the nucleus. The formation of a 'pearl sac' by the mantle epithelium was considered by other authors as a cellular response different to encapsulation.

Pearl or pearl-like calcareous concretions have been reported in a great number of bivalves (Lauckner, 1983). From the evidence obtained from the present study and by the data reported by Ituarte et al. (2001), the secretion of calcium carbonate in the form of nacre (tablet-like crystals of calcite) or other mineralogical form of calcium carbonate seems to be the last step in a successful host reaction in an attempt to isolate a strange body. When the strange body or foreign material is a digenean larva, secretion of calcium carbonate does not take place unless the parasite is dead; otherwise, the parasite metabolism seems to prevent, in an unknown way, calcium deposition. A particular case in which both the survivorship of larvae and deposition of calcium carbonate have been preserved through the evolution of clam and parasite life cycles, is that reported for several gymnophallid species by Campbell (1985) and Ituarte et al. (2001). In these cases, an incomplete calcium carbonate cover, allowing the larvae survival, surrounds metacercariae in the extrapallial space.

Throughout the evolution of gymnophalids, a life-cycle model comprising the longest period of their life as unencysted metacercariae within a second intermediate host (mainly in the extrapallial space of the bivalve) has been selected as the most adaptive. Then, well adjusted strategies of host reaction avoidance are expected. In this sense, nacrezation, a process that determines the larvae death, 
should be considered the final stage in a successful host response against parasites instead of a trait in the parasite life cycle.

Nacrezation should be considered a particular case of encapsulation, which starts in the extrapallial space and leads to the formation of a sac limited by a one-cell-thick layer originated in an invagination of the mantle epithelium to engulf a foreign particle. This 'pearl sac' secretes a calcium carbonate material covering the engulfed particle to form a pearl (in those cases in which the pearl sac is detached from the outer mantle epithelium) or a blister (when the pearl sac is represented by an invagination of the outer epithelium that remains bound to the mantle). In that sense, nacrezation is referring to the cellular defence mechanism, which starts in the extrapallial space, and in which the main reaction tissue is the mantle epithelium. Its cells are metabolically active, and they increase secretion trying to isolate the foreign particle.

Cheng \& Rifkin (1970) gave the host response of Cerastoderma edule to Meiogymnophallus minutus early described by Bowers \& James (1967) as an example of nacrezation. However, these authors were unable to explain why the metacercariae of $M$. minutus 'did not induce calcium secretion'. Based on the present results, the reaction elicited by M. minutus should be considered as a case of encapsulation.

The authors are grateful to Luis O. Bala and to Juan Escobar (Centro Nacional Patagónico, Puerto Madryn, Argentina) for their help in the field and laboratory works. The technical assistance of Emilio Topa (CEPAVE) and Rafael Urréjola (Museo de La Plata Scanning Electron Microscope unit) is greatly appreciated. This study was partially funded by a Lerner-Gray Grant (American Museum of Natural History) to F. Cremonte. F. Cremonte and C.F. Ituarte are members of the National Research Council for Science and Technology (CONICET).

\section{REFERENCES}

Bartoli, P., 1974. Recherches sur les Gymnophallidae F.N. Morozov, 1955 (Digenea) parasites d'oiseaux des côtes de Camargue: systématique, biologie et ecologie. Marseille. Thése de Doctorat d'Etat, Université de Droit, d'Economie et des Sciences Dáix-Marseille, Faculté des Sciences et Techniques de Saint-Jérôme, France.

Bartoli, P., 1981. Démographie et phénomène de compétition intraspécifique des Gymnophallidae Morozov, 1955 chez les deuxièmes hôtes intermédiaires. Annales de Parasitologie, 56, 33-44.

Bowers, E.A., Bartoli, P., Russell-Pinto, F. \& James, B.L., 1996. The metacercariae of sibling species of Meiogymnophallus including M. rebequi comb. nov. (Digenea: Gymnophallidae), and their effects on closely related Cerastoderma host species (Mollusca: Bivalvia). Parasitology Research, 82, 505-510.
Bowers, E.A. \& James, B.L., 1967. Studies on the morphology, ecology and life-cycle of Meiogymnophallus minutus (Cobbold, 1859) comb. nov. (Trematoda: Gymnophallidae). Parasitology, 57, 281-300.

Bush, A.O., Lafferty, K.D., Lotz, J.M. \& Shostak, A.W., 1997. Parasitology meets ecology on its own terms: Margolis et al. revisited. Fournal of Parasitology, 83, 575-583.

Campbell, D., 1985. The life cycle of Gymnophallus rebecqui (Digenea: Gymnophallidae) and the response of the bivalve Abra tenuis to its metacercariae. Fournal of the Marine Biological Association of the United Kingdom, 65, 589-601.

Carcelles, A.R., 1950. Catálogo de los moluscos marinos de Patagonia. Anales del Museo Nahuel Huapi, 2, 41-109.

Cheng, T.A., 1967. Marine molluscs as hosts for symbioses with a review of known parasites of commercially important species. Advances in Marine Biology, 5, 1-424.

Cheng, T.C. \& Rifkin, E., 1970. Cellular reactions in marine molluscs in response to helminth parasitism. In A symposium on diseases of fishes and shellfishes (ed. S.F. Snieszko), pp. 443-496. Washington D.C.: American Fisheries Society.

Ching, H.L., 1995. Evaluation of characters of the family Gymnophallidae Morozov, 1955. Canadian Fournal of Fisheries and Aquatic Sciences, 52 (Suppl. 1), 78-83.

Cremonte, F., 2001. Bartolius pierrei n.g. n.sp. (Digenea: Gymnophallidae) from Península Valdés. Argentina. Systematic Parasitology, 49, 139-147.

Feng, S.Y., 1988. Cellular defense mechanisms of oysters and mussels. In Disease processes in marine bivalve molluscs (ed. W.S. Fisher), pp.153-168. Bethesda: American Fisheries Society.

Fletcher, T.C. \& Cooper-Willis, C.A., 1982. Cellular defense systems of the Mollusca. In The reticulo-endothelial system. A comprehensive treatise. Phylogeny and ontogeny. (ed. N. Cohen and M.M. Siegel), pp. 141-166. New York: Plenum Press.

Gabe, M., 1968, Techniques histologiques. Paris: Masson.

Goater, G.P., 1993. Population biology of Meiogymnophallus minutus (Trematoda: Gymnophallidae) in cockles from the Exe Estuary. Fournal of the Marine Biological Association of the United Kingdom, 73, 163-177.

Ituarte, G.F., Cremonte, F. \& Deferrari, G., 2001. Mantle-shell complex reactions elicited by digenean metacercariae in Gaimardia trapesina (Lamarck, 1819) (Bivalvia: Gaimardiidae) from the Southwestern Atlantic Ocean and Magellan Strait. Diseases of Aquatic Organisms, 48, 47-56.

Jameson, H.L., 1902. On the origin of pearls. Proceedings of the Zoological Society of London, 1, 140-166.

Lauckner, G., 1983. Diseases of Mollusca: Bivalvia. In Diseases of marine animals (ed. O. Kinne), pp. 477-961. Hamburg: Biologische Anstalt Helgoland.

Pekkarinen, M., 1984. Anatomy, histology and maturing of metacercaria of Lacunovermis macomae (Trematoda: Gymnophallidae) from brackish-water Macoma balthica (southwestern Finland, Baltic Sea). Annales Zoologici Fennici, 21, 481-498.

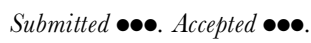

